\title{
Extending the ASS1ST active space selection scheme to large molecules and excited states
}

\author{
Abhishek Khedkar and Michael Roemelt* \\ Lehrstuhl für Theoretische Chemie, Ruhr-Universität Bochum, D-44780 Bochum, Germany \\ E-mail: michael.roemelt@theochem.rub.de \\ Supporting Information
}

\section{Contents}

Supporting Information

A: CASSCF active natural orbitals and their occupancies

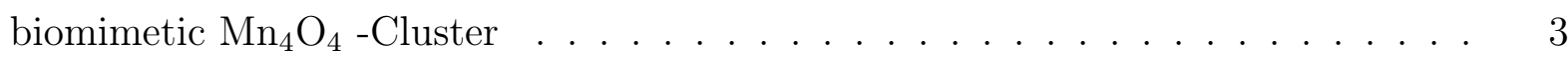

Oxotetrachlorovanadate(IV) anion . . . . . . . . . . . . . . . 4

$\mathrm{CH}_{3} \mathrm{Mn}(\mathrm{CO})_{3}(\alpha$-diimine $) \ldots \ldots \ldots \ldots \ldots$

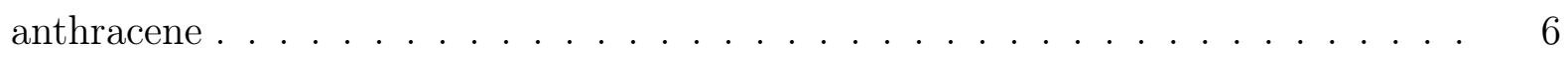

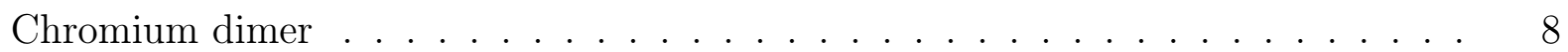

B: Quasi-natural orbitals and their occupation numbers from ASSIST calcu$\begin{array}{ll}\text { lations } & 9\end{array}$

biomimetic $\mathrm{Mn}_{4} \mathrm{O}_{4}$-Cluster . . . . . . . . . . . . . . . . . . . 9

Oxotetrachlorovanadate (IV) anion . . . . . . . . . . . . . . 10

$\mathrm{CH}_{3} \mathrm{Mn}(\mathrm{CO})_{3}(\alpha$-diimine $) \ldots \ldots \ldots \ldots \ldots \ldots$ 


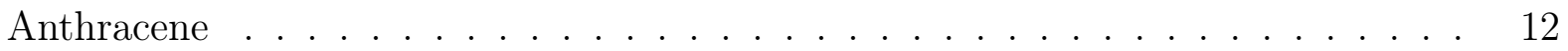

Chromium dimer $\left(\mathrm{Cr}_{2}\right) \ldots \ldots \ldots \ldots \ldots \ldots \ldots \ldots$

$\begin{array}{ll}\mathrm{C}: \mathrm{Ni}(\mathrm{CO})_{4} & 15\end{array}$

D: DMRGSCF and NEVPT2 electronic energies (Eh) for Chromium dimer $\begin{array}{ll}\mathrm{Cr}_{2} & 23\end{array}$

$\begin{array}{ll}\text { E: Optimized XYZ Geometries } & 24\end{array}$

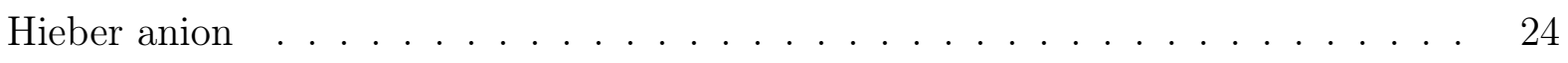

Oxotetrachlorovanadate(IV) anion . . . . . . . . . . . . . . . 24

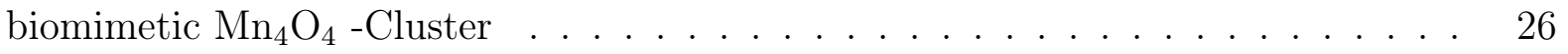

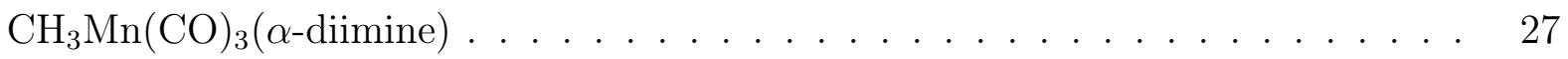

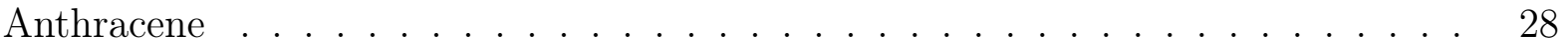




\title{
A: CASSCF active natural orbitals and their occupancies
}

\author{
biomimetic $\mathrm{Mn}_{4} \mathrm{O}_{4}$-Cluster
}
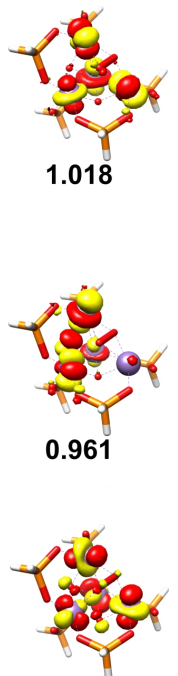

0.974
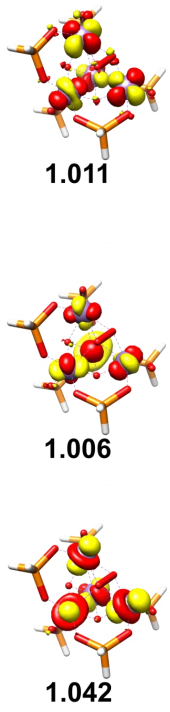
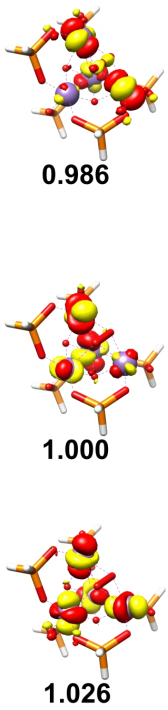
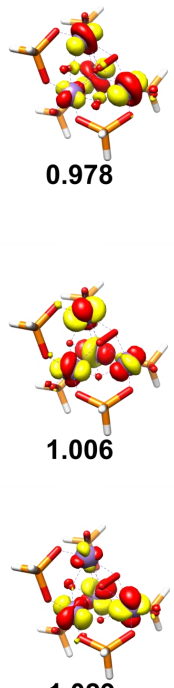

1.029
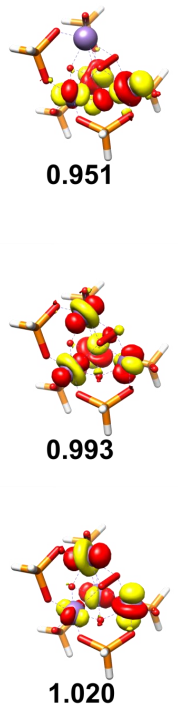

Figure S1: The $(15,15)$ active orbitals for the quartet state of complex 2
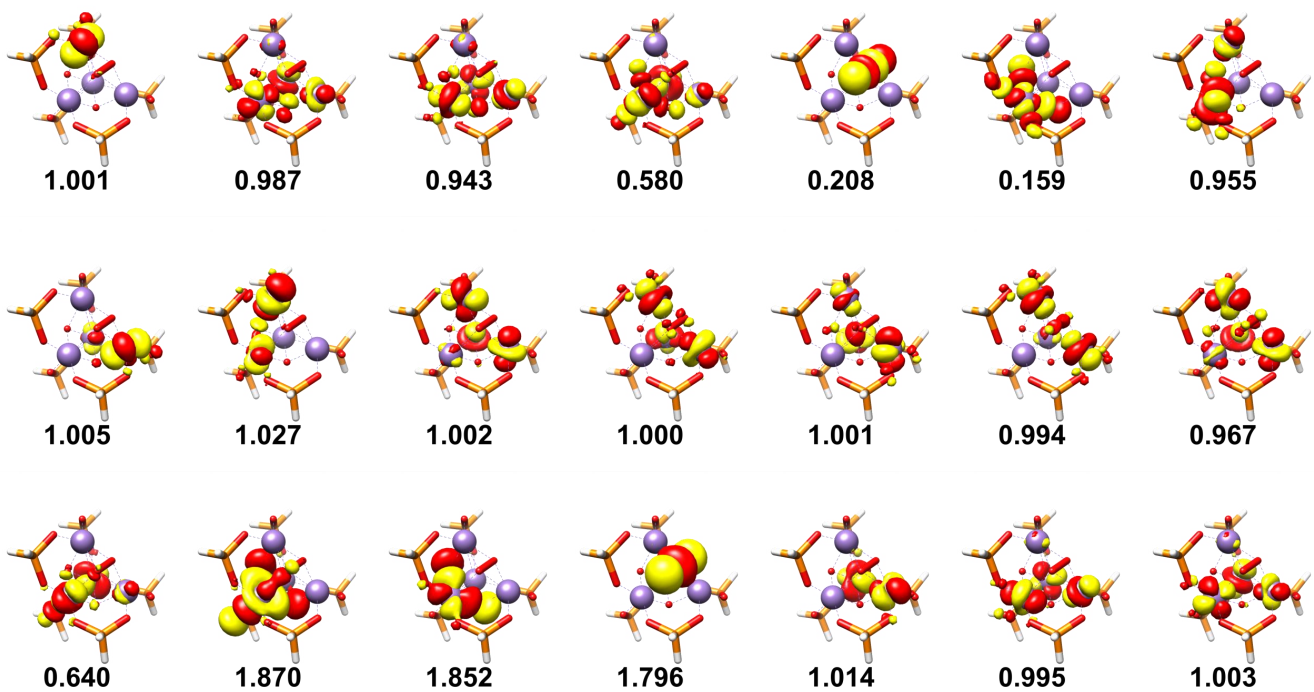

Figure S2: The $(21,21)$ active orbitals for the quartet state of complex $\mathbf{2}$ 
Oxotetrachlorovanadate(IV) anion
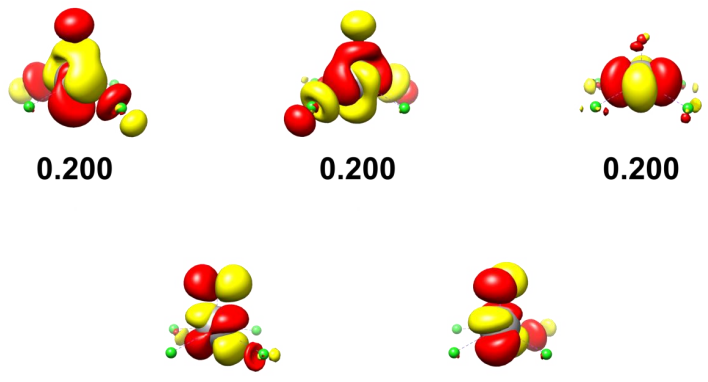

0.200

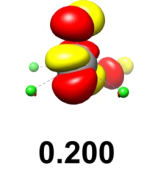

Figure S3: The ${ }^{5 \mathrm{~d}} \mathrm{SA}-\mathrm{CASSCF}(1,5)$ active orbitals of complex 3

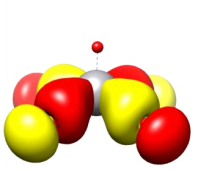

1.989

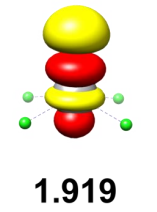

1.919

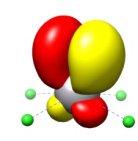

1.897

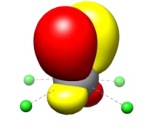

1.897
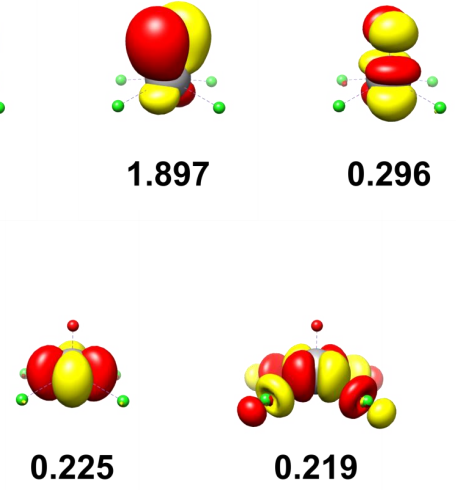

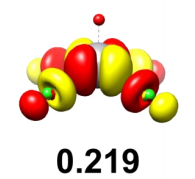

Figure S4: The ${ }^{5 \mathrm{~d}} \mathrm{SA}-\mathrm{CASSCF}(9,9)$ active orbitals of complex $\mathbf{3}$ 


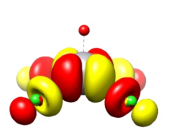

0.220

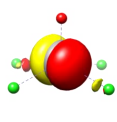

1.993

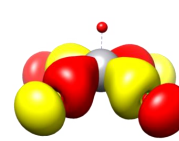

1.990
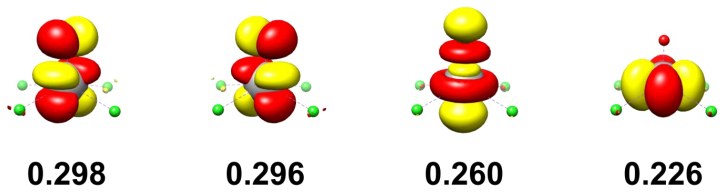

Figure S5: The ${ }^{5 \mathrm{~d}} \mathrm{SA}-\mathrm{CASSCF}(11,10)$ active orbitals of complex 3

\section{$\mathrm{CH}_{3} \mathrm{Mn}(\mathrm{CO})_{3}(\alpha$-diimine $)$}
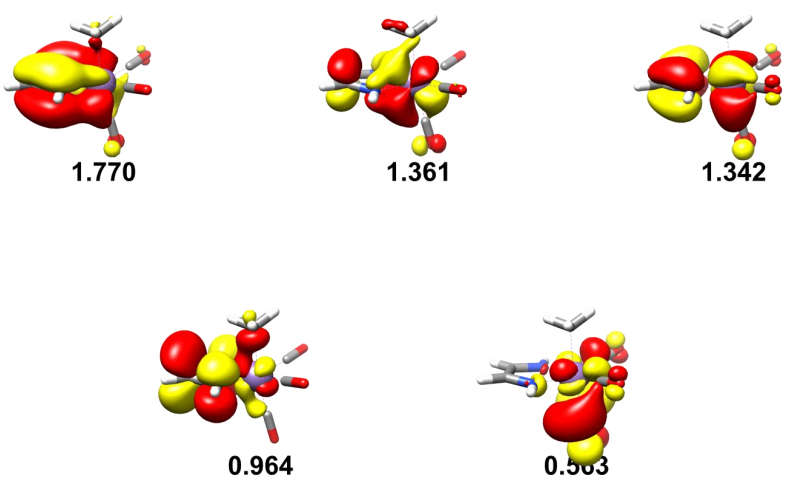

Figure S6: The ${ }^{10 \text { s }}$ SA-CASSCF $(6,5)$ active orbitals complex 4 

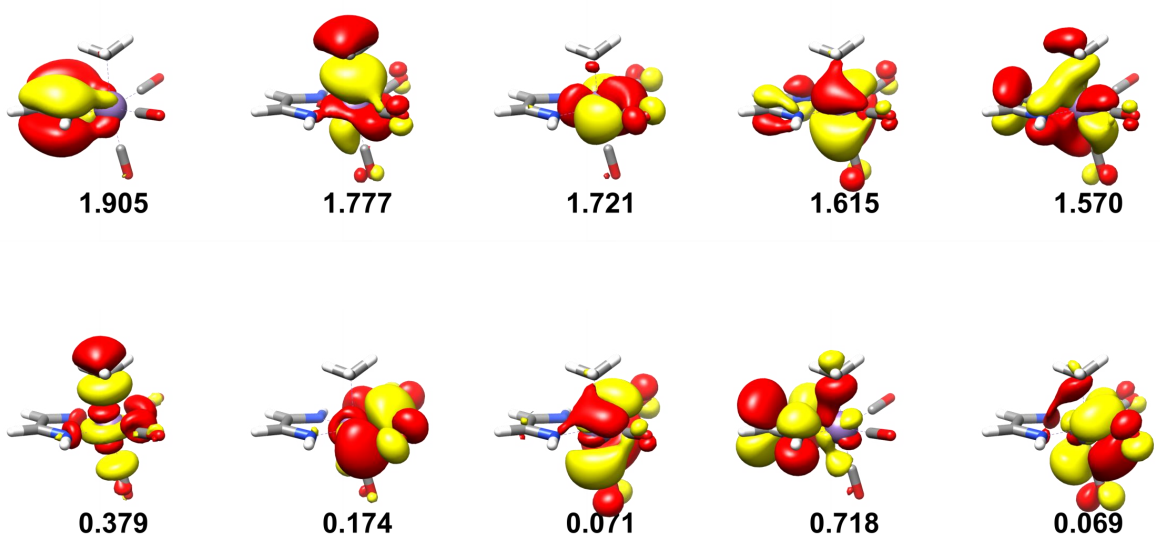

Figure S7: The ${ }^{10 \text { s }}$ SA-CASSCF $(10,10)$ active orbitals complex 4

\section{anthracene}
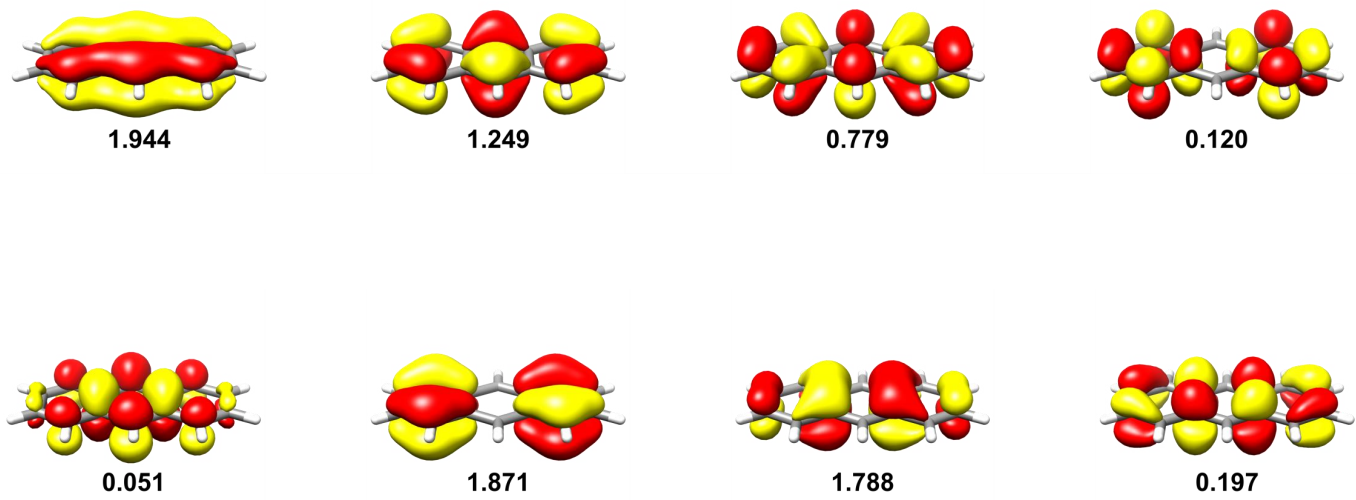

Figure S8: The ${ }^{4 \mathrm{~s} A-C A S S C F}(8,8)$ active orbitals of complex $\mathbf{5}$ 

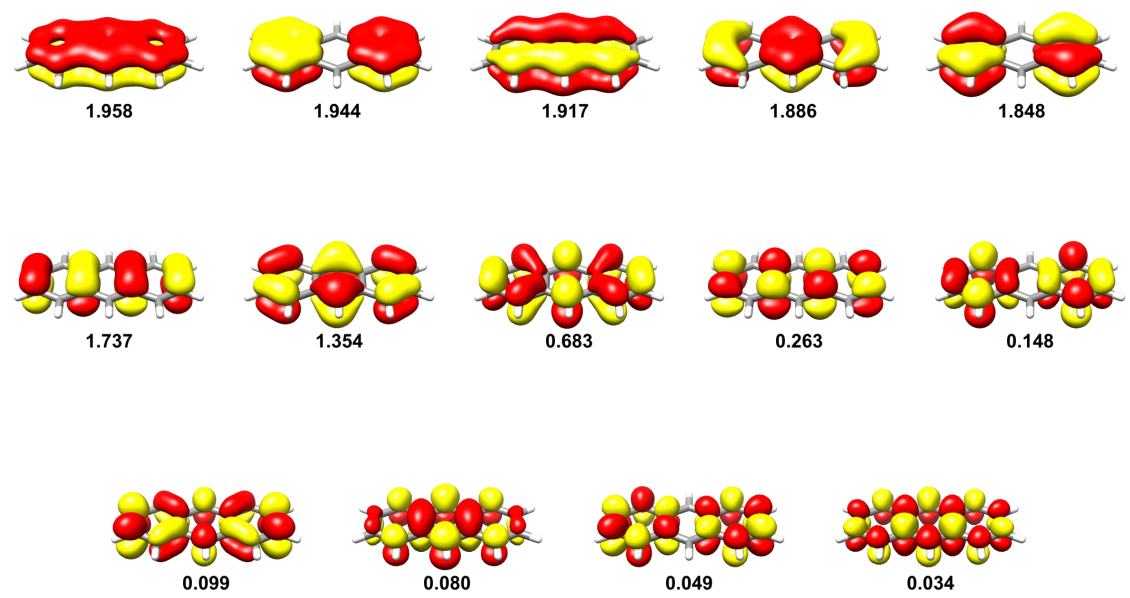

Figure S9: The ${ }^{4 s}$ SA-CASSCF $(14,14)$ active orbitals of complex $\mathbf{5}$ 


\section{Chromium dimer}
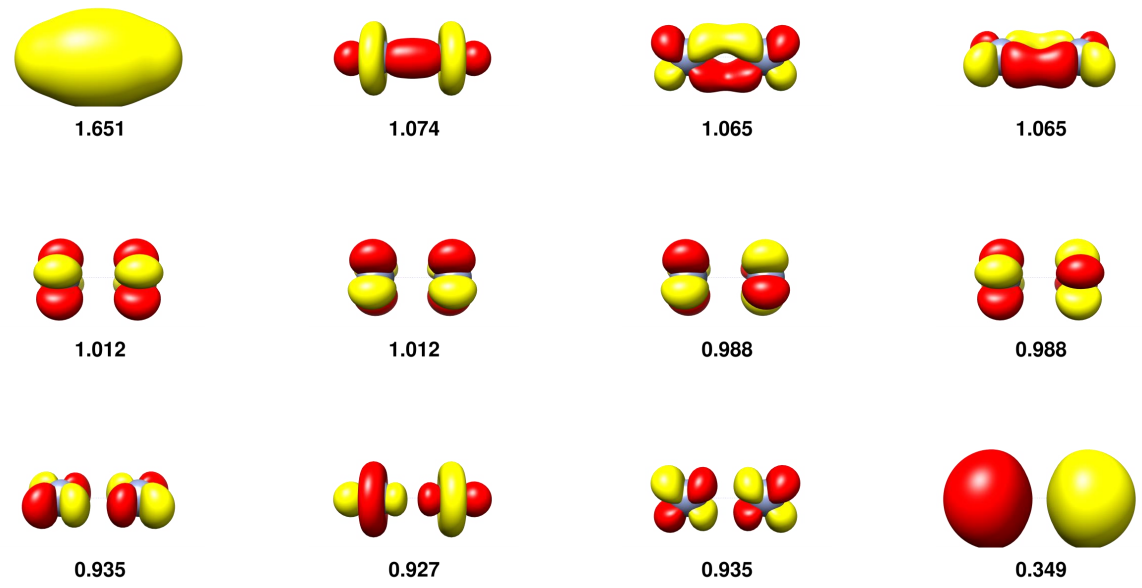

Figure S10: $\operatorname{CASSCF}(12,12)$ active orbitals of $\mathrm{Cr}_{2}$ at $\mathrm{r}=3.00 \AA$

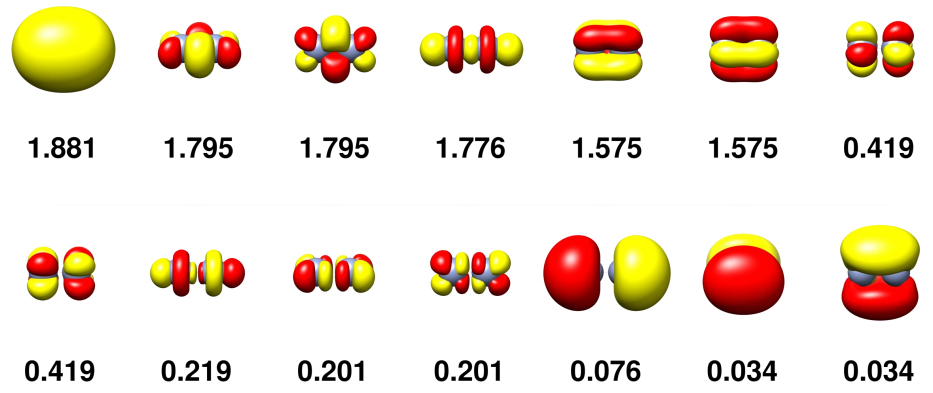

Figure S11: CASSCF $(12,14)$ active orbitals of $\mathrm{Cr}_{2}$ at $\mathrm{r}=1.678 \AA$ 


\section{B: Quasi-natural orbitals and their occupation numbers from ASSIST calculations}

biomimetic $\mathrm{Mn}_{4} \mathrm{O}_{4}$-Cluster

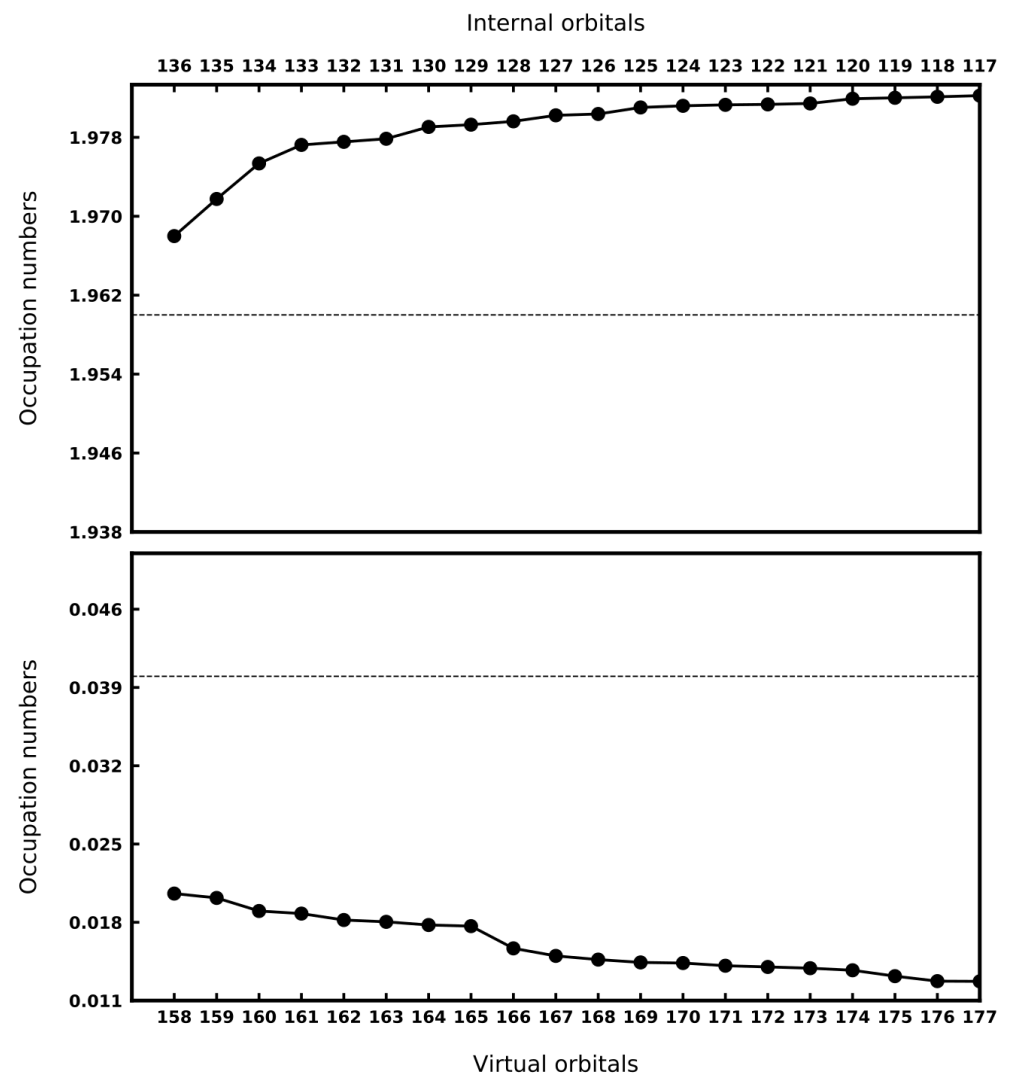

Figure S12: ASS1ST $(21,21)$ for complex 2 


\section{Oxotetrachlorovanadate(IV) anion}

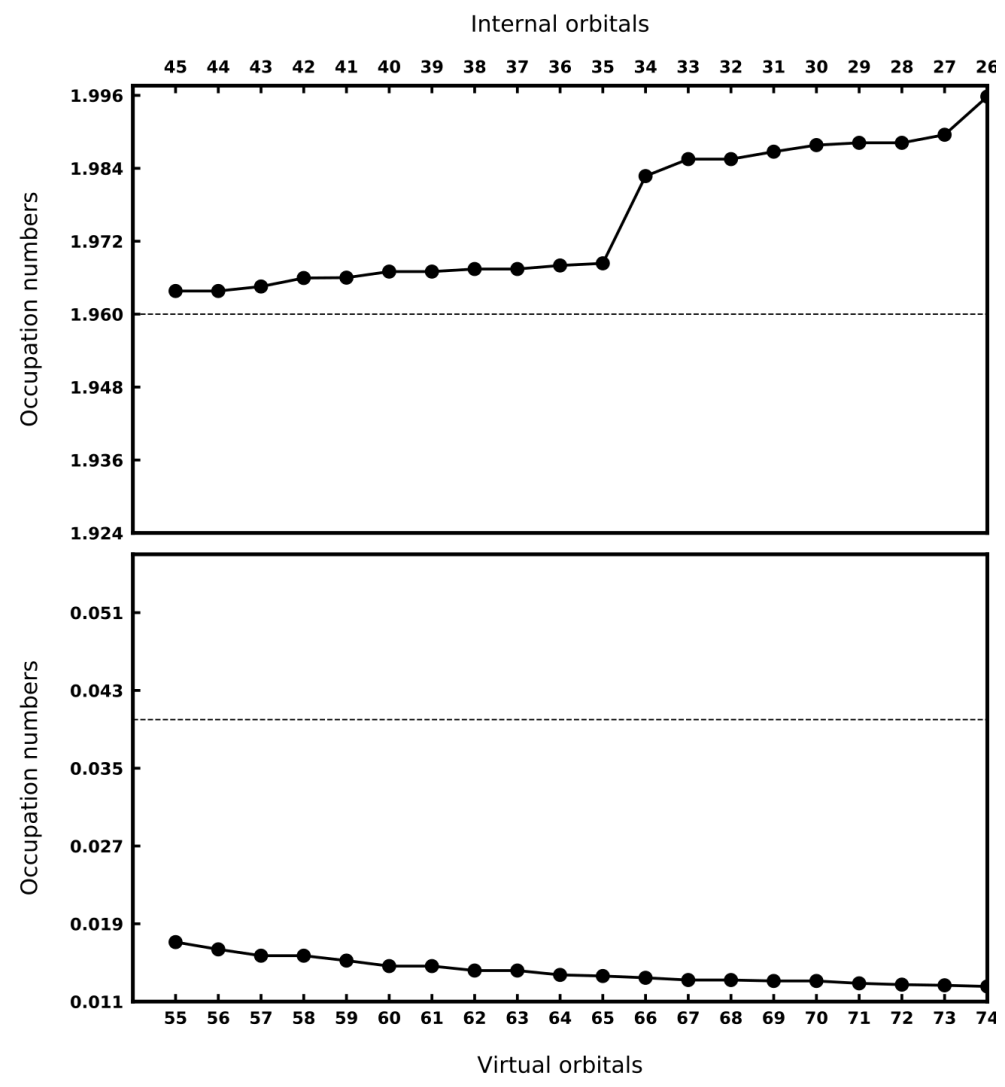

Figure S13: ${ }^{5 \mathrm{~d}} \mathrm{SA}-\mathrm{ASS} 1 \mathrm{ST}(9,9)$ for complex 3 


\section{$\mathrm{CH}_{3} \mathrm{Mn}(\mathrm{CO})_{3}(\alpha$-diimine $)$}

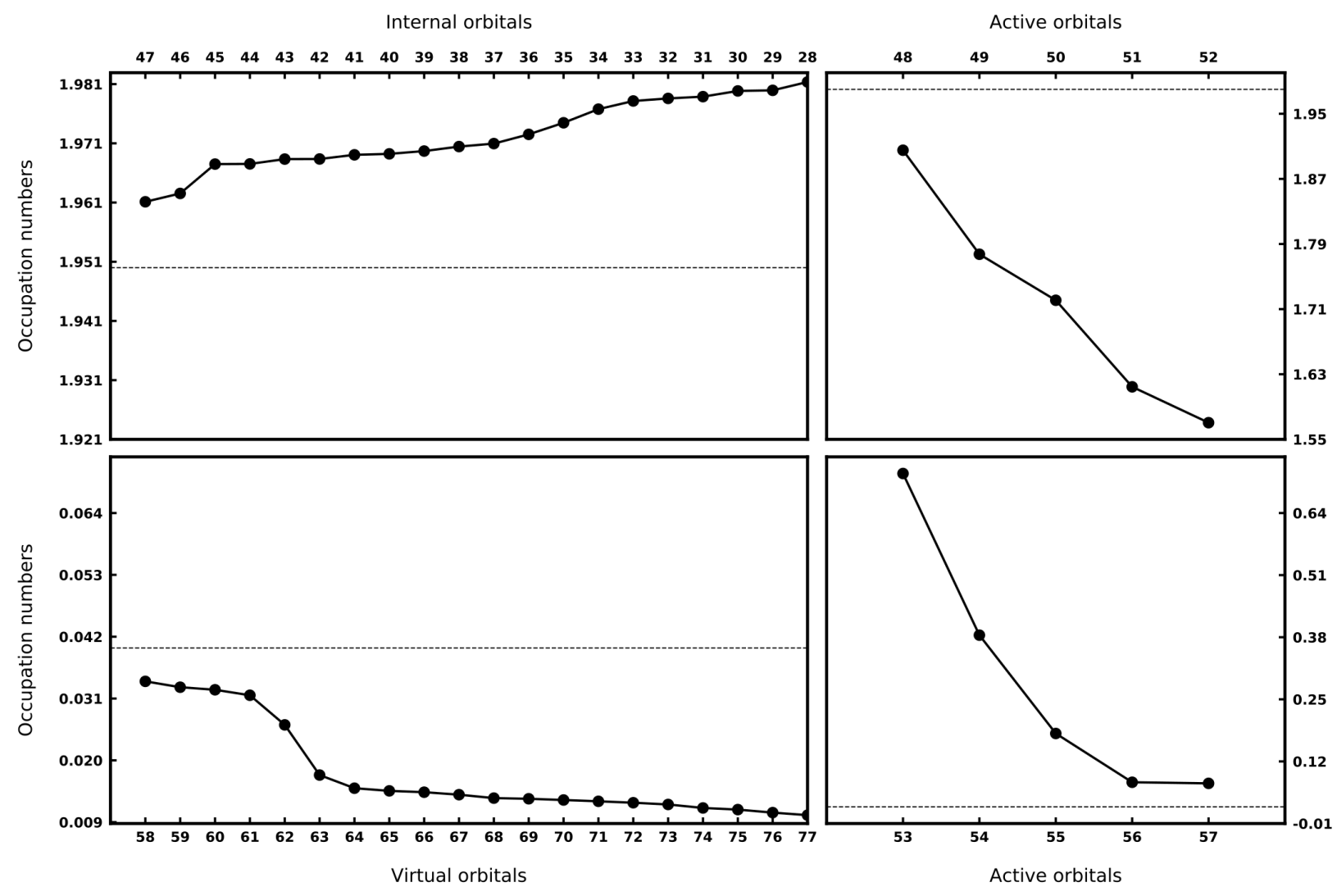

Figure S14: ${ }^{10 s} \mathrm{SA}-\mathrm{ASS} 1 \mathrm{ST}(10,10)$ for complex 4 


\section{Anthracene}

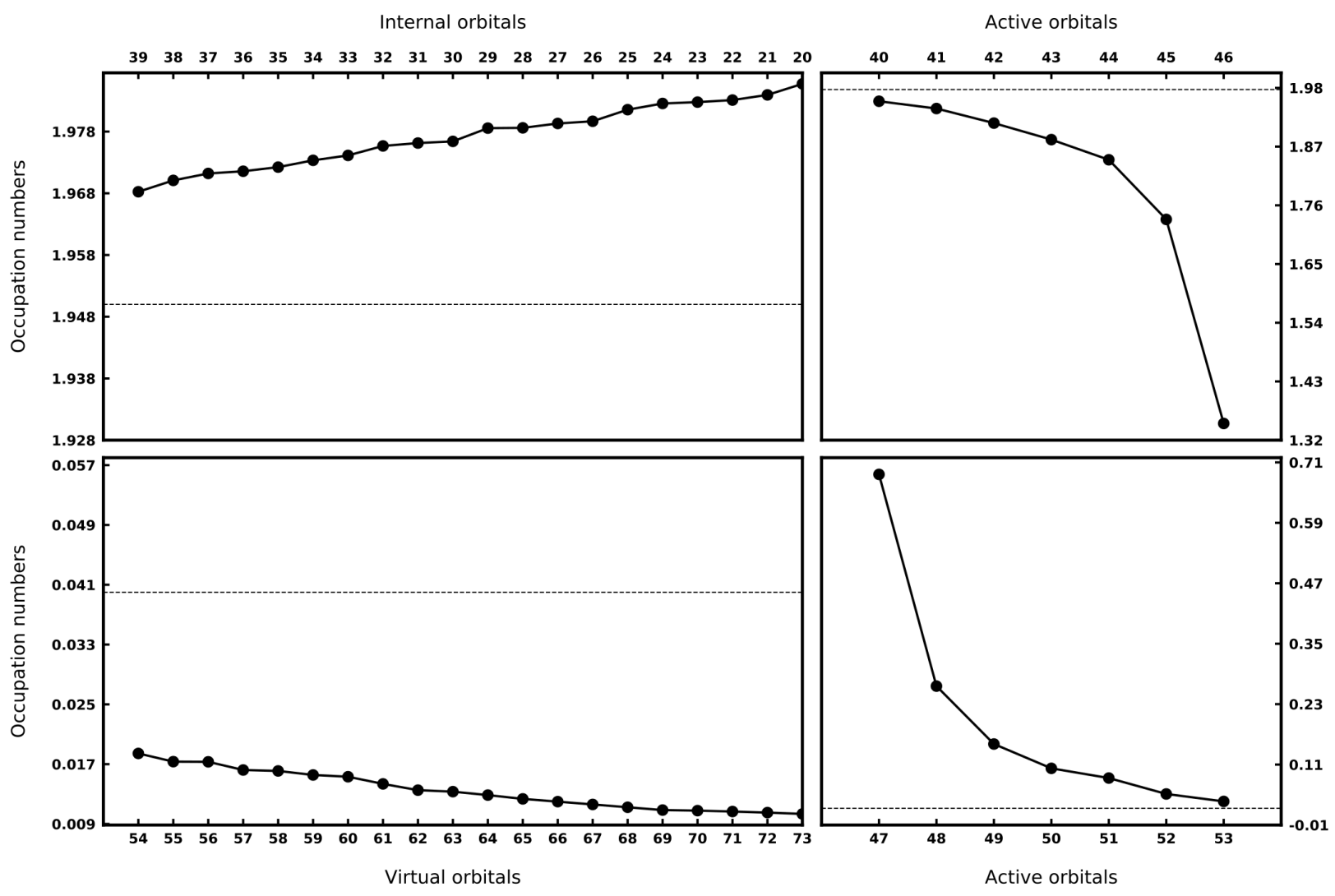

Figure S15: ${ }^{4 s}$ SA-ASS1ST $(14,14)$ for complex $\mathbf{5}$ 


\section{Chromium dimer $\left(\mathrm{Cr}_{2}\right)$}

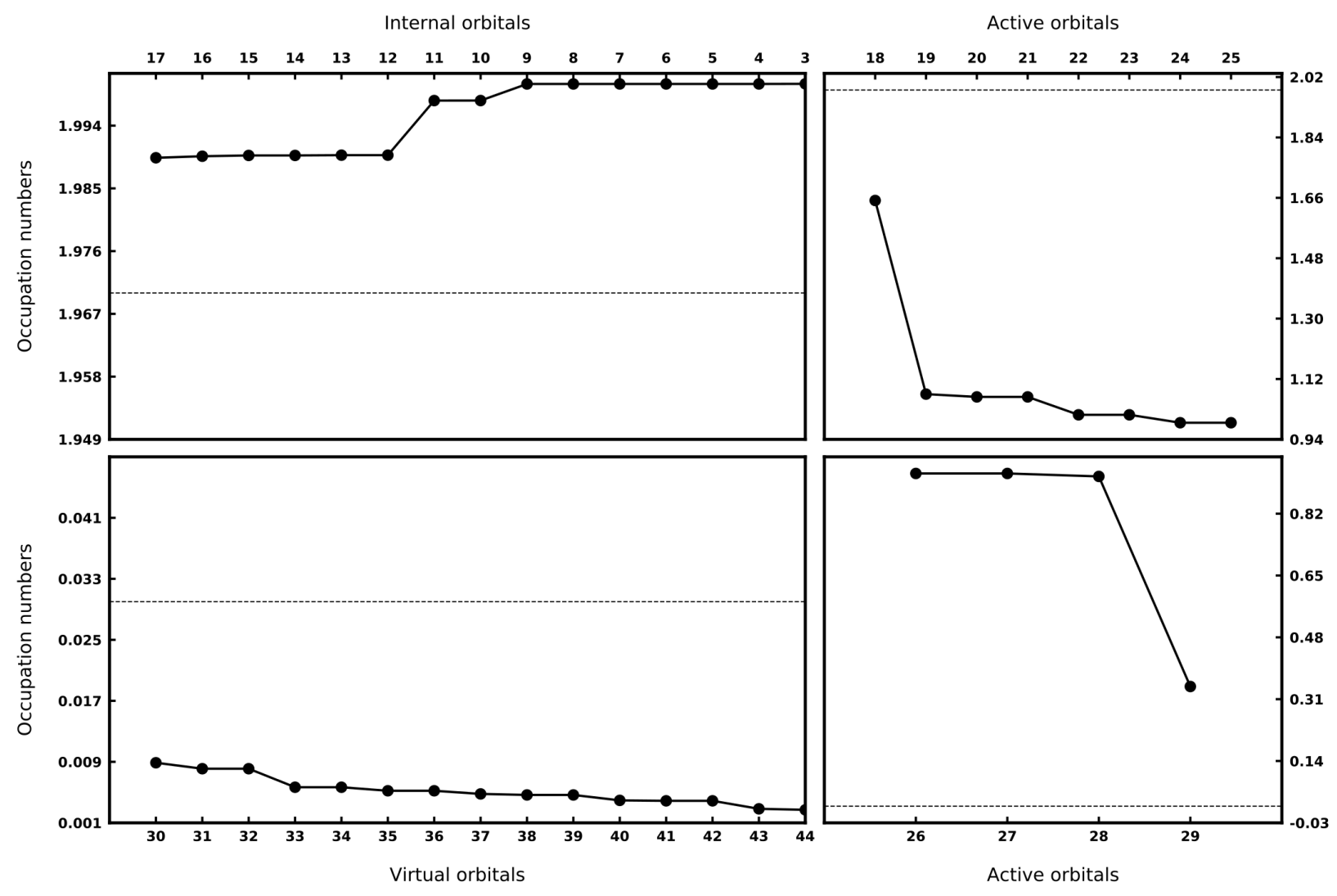

Figure S16: $\operatorname{ASS1ST}(12,12)$ for $\mathrm{Cr}_{2}$ at $\mathrm{r}=3.0 \AA$ 


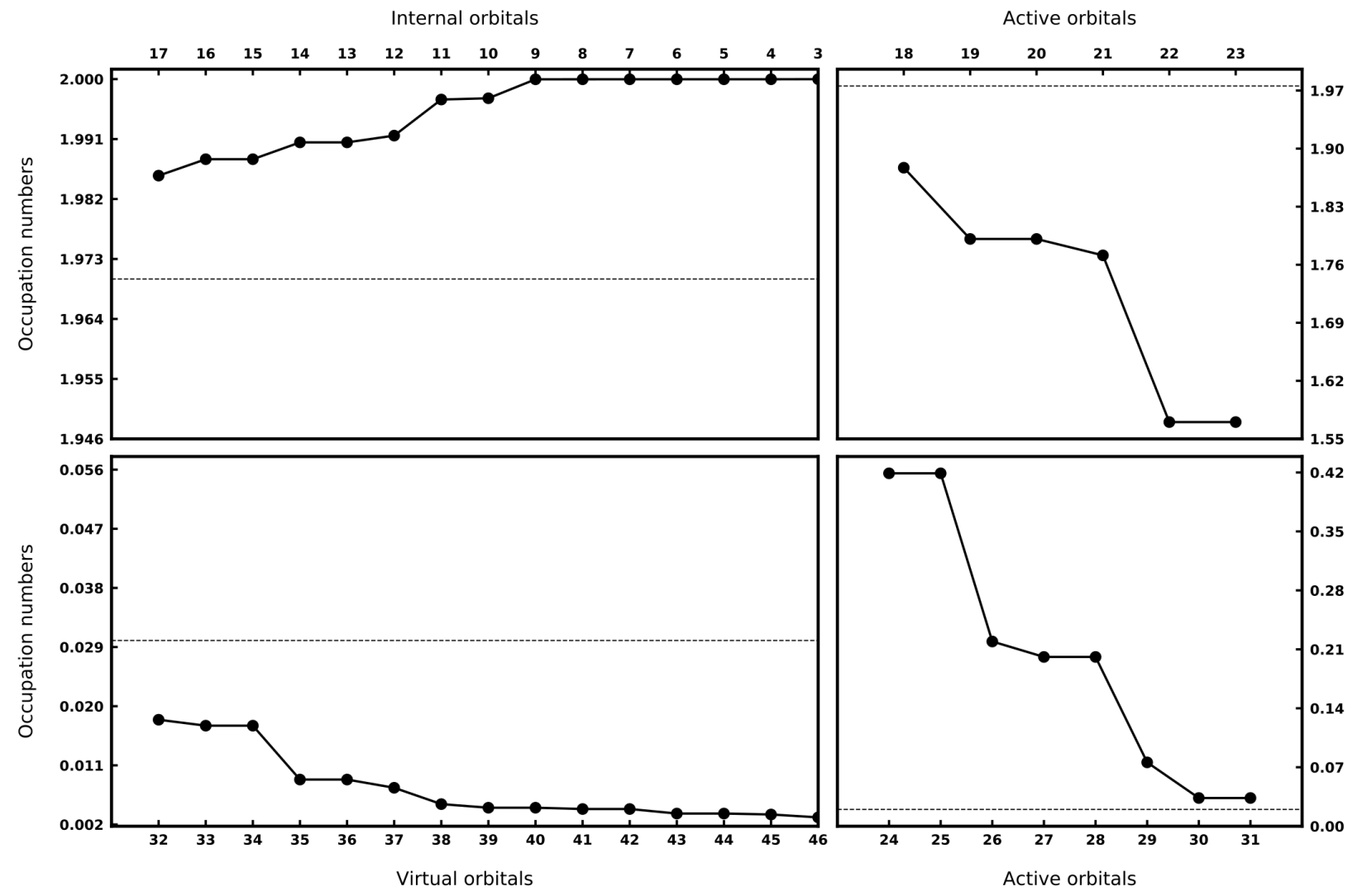

Figure S17: $\operatorname{ASS1ST}(12,14)$ for $\mathrm{Cr}_{2}$ at $\mathrm{r}=1.678 \AA$ 


\section{$\mathrm{C}: \mathrm{Ni}(\mathrm{CO})_{4}$}

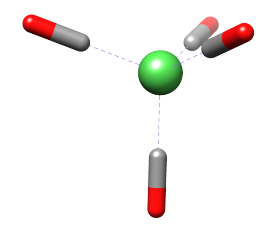

Figure S18: Complex S1

The performance of ASS1ST was tested with a late transition metal complex $\mathrm{Ni}(\mathrm{CO})_{4}$. The highly symmetric tetrahedral Nickel carbonyl denoted as complex $\mathbf{S} 1$ serves as an important model system of transition metal carbonyls as well as bonding of CO to the metal surfaces. With multiple allowed MLCT excitations and in the absence of ligand field $\mathrm{d} \rightarrow \mathrm{d}$ transitions, assigning the experimental spectral bands becomes a challenge for the complex S1.

The first set of calculations targeted the ground state of $\mathbf{S 1}$. Owing to the $d^{10}$ system, a routine choice of 10 electrons in 10 orbitals which contains a mixture of CO $\pi^{*}$ and $3 d^{\prime}$ character was chosen as an initial active space for ASS1ST as shown in figure S19. The $(10,10)$ choice coincides with the active space chosen by multiple studies ((J. Chem. Phys. 1994, 101, 6810 and J. Phys. Chem. 1996, 100, 16545-16550 and Int. J. Quantum Chem. 2011, 111, 3291-3301)). The ASS1ST(10,10) NOON distribution shown in Figure S20 suggested the inclusion of three additional virtual orbitals to the active space as shown in the figure S21. 


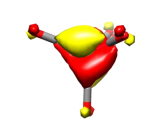

1.957

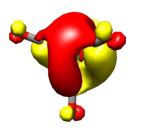

0.050

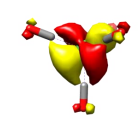

1.957

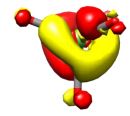

0.050

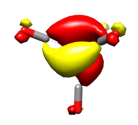

1.950

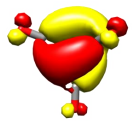

0.050

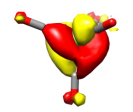

1.950

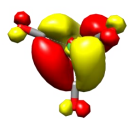

0.043
1.950
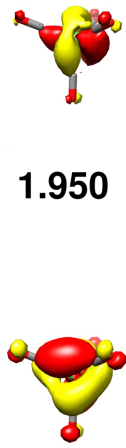

0.043

Figure S19: CASSCF $(10,10)$ active natural orbitals and their occupation numbers for complex $\mathbf{S} 1$

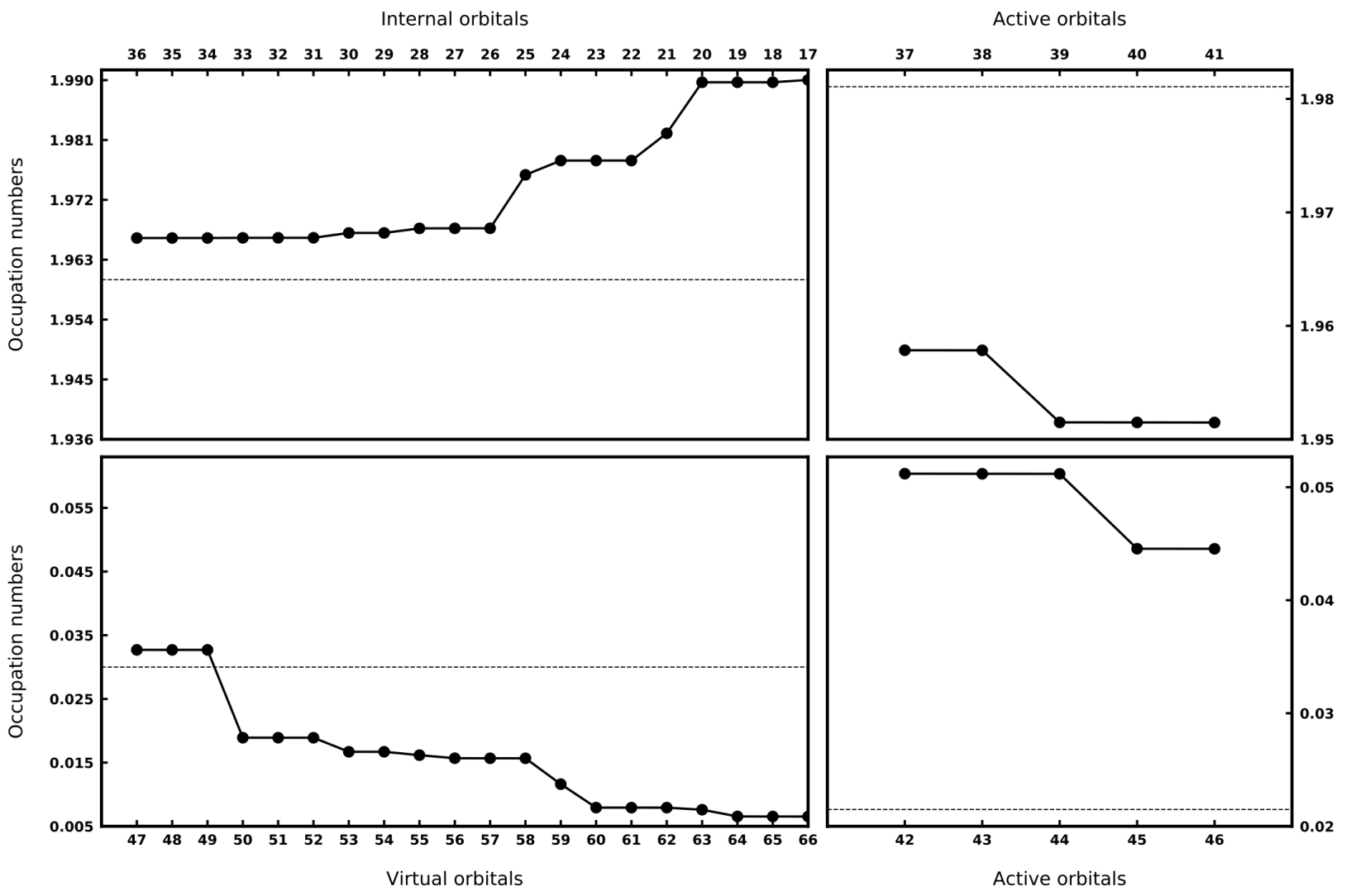

Figure S20: ASS1ST(10,10) for complex S1 


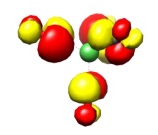

0.033

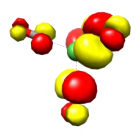

0.033

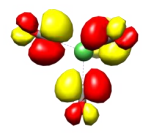

0.033

Figure S21: Three virtual orbitals and their occupation numbers from ASS1ST(10,10) for complex S1

An independent calculation with the additional second d-shell included in the active space was performed leading to $\operatorname{CASSCF}(10,15)$ as shown in figure $\operatorname{S22}$. ASS1ST $(10,15)$ NOON distribution indicates the same three additional virtual orbitals (see figure S21) to be included as shown in the figure S23. Before proceeding further, it should be noted that the five orbitals as shown in the figure S22 comprising the second d-shell would be reassigned to the virtual subspace if the ASS1ST protocol is to be followed as described in our original paper (Khedkar et. al J. Chem. Theory Comput.,2019, 15, 3522-3536). However, it has been realized by Pierloot et. al (Int. J. Quantum Chem. 2019, 111, 3291-3301) that the inclusion of the double-shell is crucial to achieve quantitative accuracy. This underlines the importance of critical assessment by the user of the active space suggested by ASS1ST (or any other selection scheme) in the context of system under study. To this end, the authors would like to emphasize that ASS1ST aims at providing a tool for theoretical chemists to improve and scrutinize their chemically motivated choice of active space. 


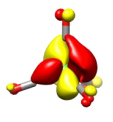

1.928

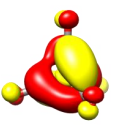

0.057

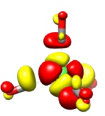

0.003

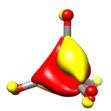

1.939

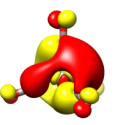

0.069

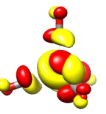

0.003

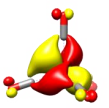

1.939

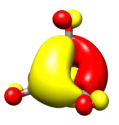

0.069

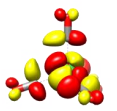

0.003
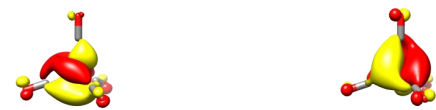

1.928

1.928
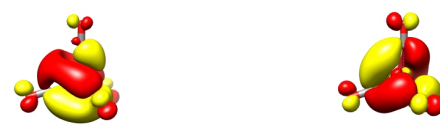

0.069

0.057
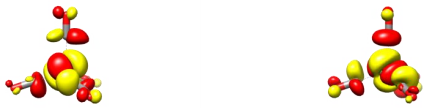

0.003

0.003

Figure S22: CASSCF $(10,15)$ active natural orbitals and their occupation numbers for complex $\mathbf{S} 1$ 


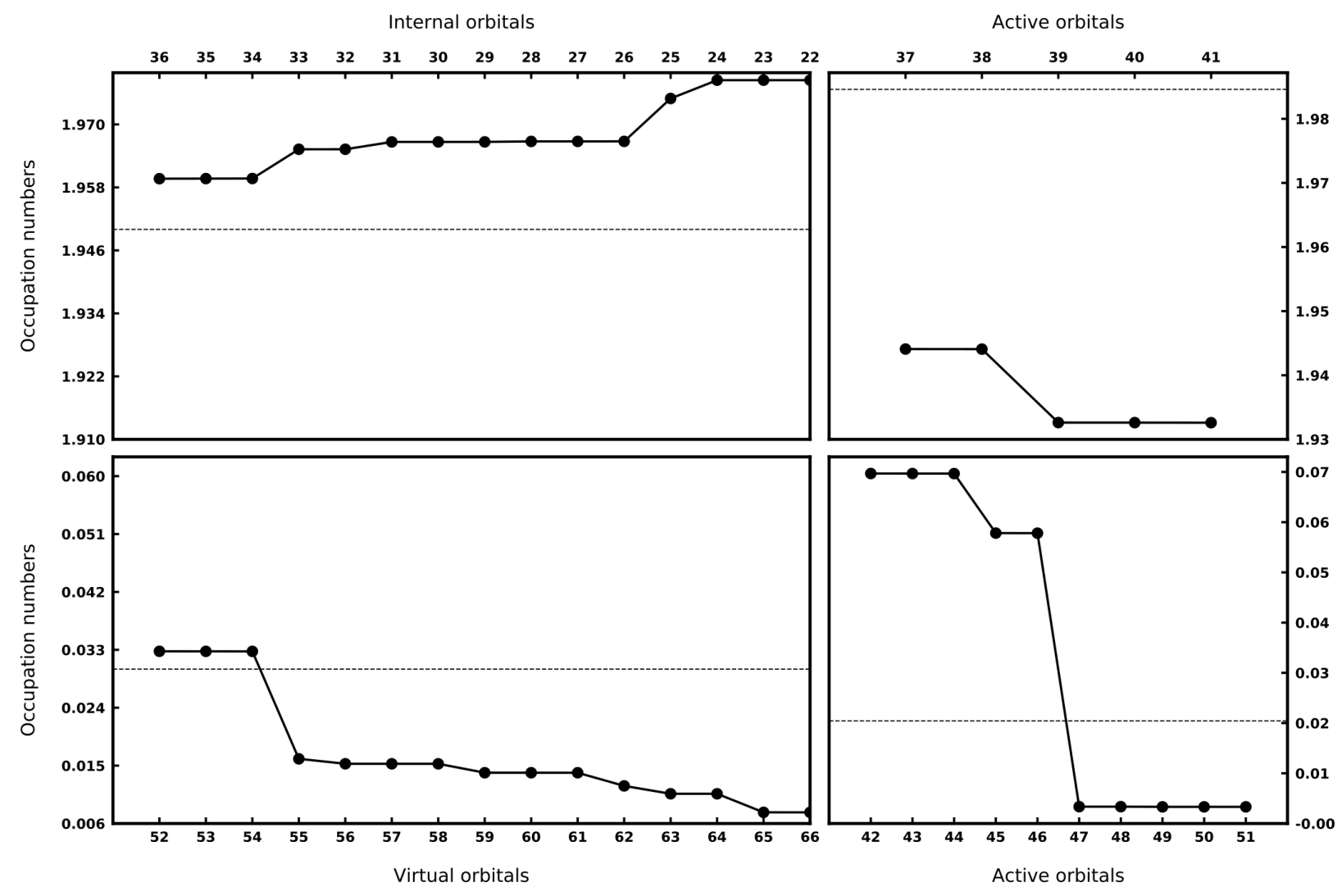

Figure S23: ASS1ST $(10,15)$ for complex S1

A second set of calculations was aimed at calculating the electronic excited states. The active space $(10,10)$ was utilized with $\operatorname{SA}-\operatorname{CASSCF}(10,10)$ calculation averaged over 12 (S $=0)$ singlet electronic states. The ${ }^{12 \mathrm{~s}} \mathrm{SA}-\mathrm{CASSCF}(10,10)$ active natural orbitals and their corresponding occupation numbers are as shown in the figure S24. 

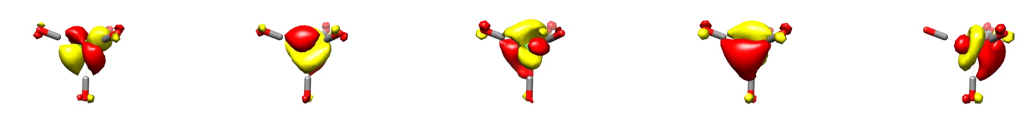

1.830

1.829

1.730

1.730

1.730
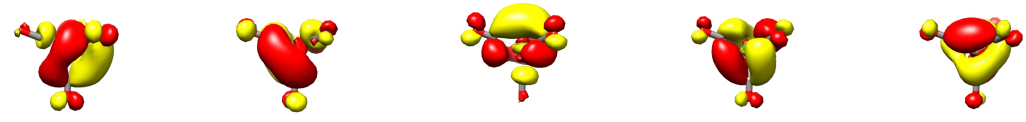

0.355

0.354

0.354

0.044

0.044

Figure S24: ${ }^{12 s}$ SA-CASSCF $(10,10)$ active natural orbitals and their occupation numbers for complex S1

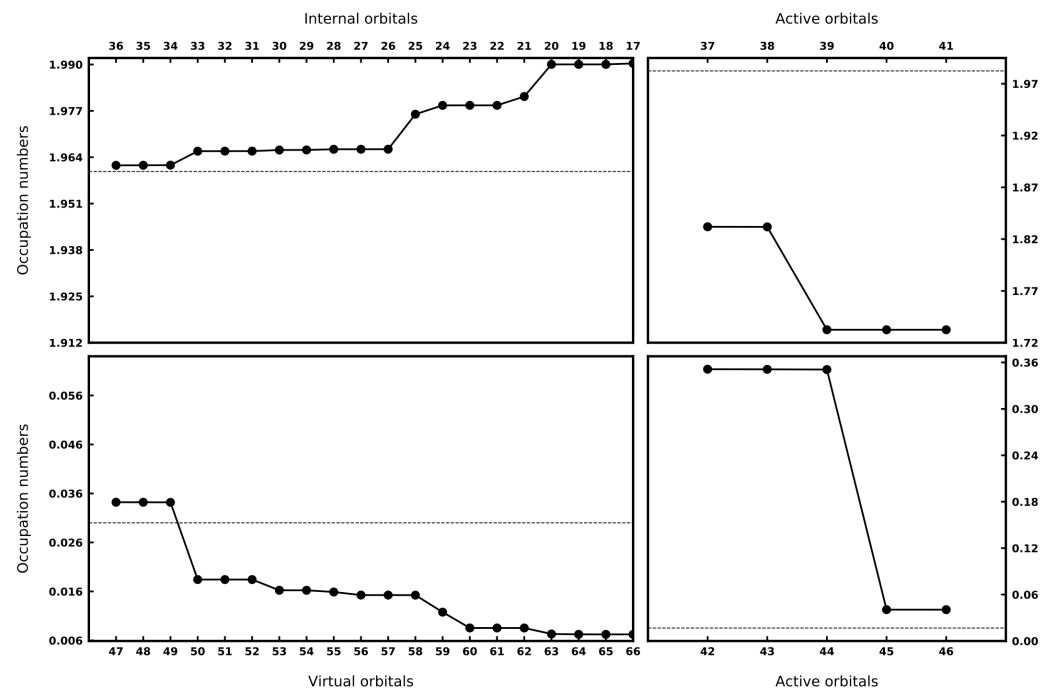

Figure S25: ${ }^{12 s}$ SA-ASS1ST $(10,10)$ for complex S1 


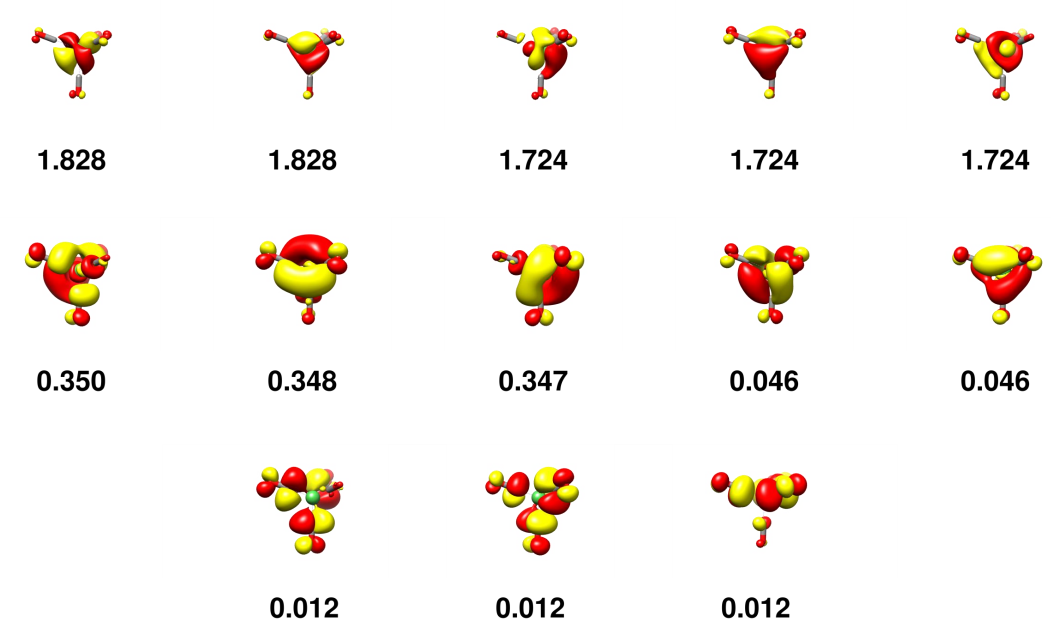

Figure S26: ${ }^{12 s} \mathrm{SA}-\mathrm{CASSCF}(10,13)$ active natural orbitals and their occupation numbers for complex S1

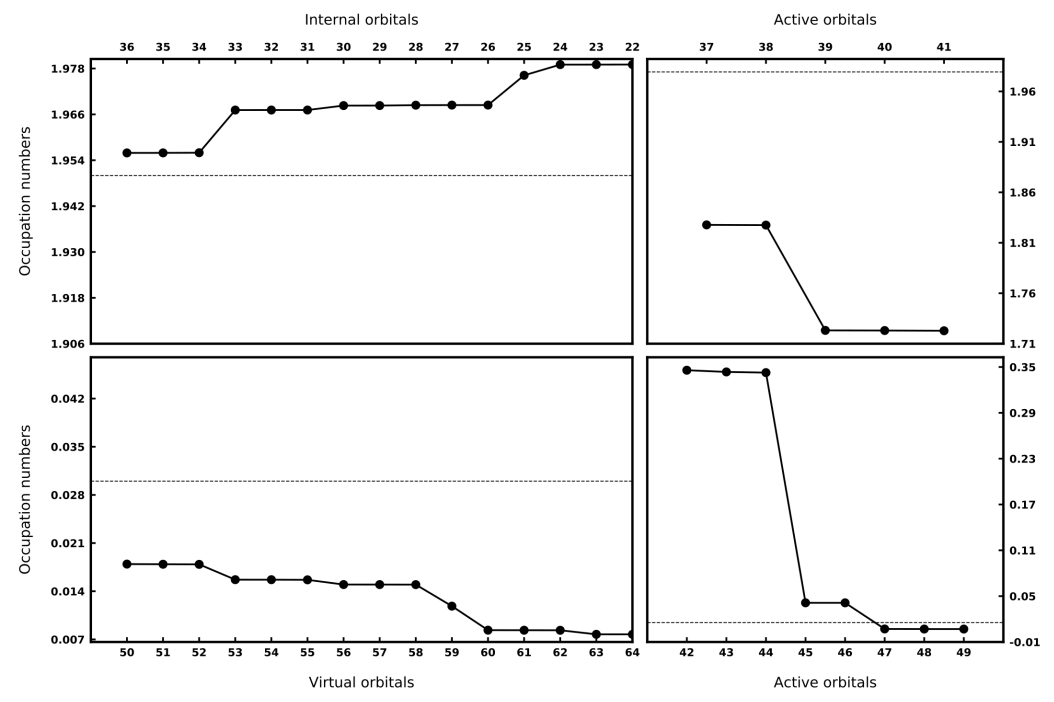

Figure S27: ${ }^{12 s} \mathrm{SA}-\mathrm{ASS} 1 \mathrm{ST}(10,13)$ for complex S1

As shown in the figure S25, ${ }^{12 s} \mathrm{SA}-\mathrm{ASS} 1 \mathrm{ST}(10,10)$ suggests inclusion of three CO $\pi^{*}$ orbitals and the resulting $(10,13)$ active space coincides with the extended $(10,13)$ space chosen by Pierloot et. al (Int. J. Quantum Chem., 111: 3291-3301) for calculating the excited states. The ${ }^{12 s} \mathrm{SA}-\mathrm{CASSCF}(10,13)$ active orbitals are shown in the figure S26. The subsequent ${ }^{12}$ SA-ASS1ST $(10,13)$ shows that no further addition to the active space is recommended as shown in the figure S27. 
The calculated excited state energies on CASSCF $+\mathrm{SC}-\mathrm{NEVPT} 2$ and CASSCF $+\mathrm{QD}-$ NEVPT2 level are summarized in Table 1.

Table 1: Calculated vertical excitation energies from the singlet ground state of $\mathrm{Ni}(\mathrm{CO})_{4}$ in $\mathrm{eV}$

\begin{tabular}{|c|c|c|c|c|c|c|}
\hline State & $\begin{array}{c}\text { CASSCF } \\
(10,10)\end{array}$ & $\begin{array}{c}\text { CASSCF+ } \\
\text { SC-NEVPT2 } \\
(10,10)\end{array}$ & $\begin{array}{c}\text { CASSCF }+ \\
\text { QD-NEVPT2 } \\
(10,10)\end{array}$ & $\begin{array}{c}\text { CASSCF } \\
(10,13)\end{array}$ & $\begin{array}{c}\text { CASSCF+ } \\
\text { SC-NEVPT2 } \\
(10,13)\end{array}$ & $\begin{array}{c}\text { CASSCF }+ \\
\text { QD-NEVPT2 } \\
(10,13)\end{array}$ \\
\hline 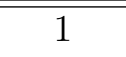 & 5.13 & 5.13 & 5.66 & 5.09 & 5.09 & 5.09 \\
\hline 2 & 5.12 & 5.12 & 5.66 & 5.09 & 5.09 & 5.09 \\
\hline 3 & 5.12 & 5.12 & 5.67 & 5.09 & 5.09 & 5.09 \\
\hline 4 & 5.23 & 5.23 & 5.80 & 5.20 & 5.20 & 5.20 \\
\hline 5 & 5.23 & 5.23 & 5.80 & 5.20 & 5.20 & 5.20 \\
\hline 6 & 5.41 & 5.41 & 6.03 & 5.40 & 5.40 & 5.40 \\
\hline 7 & 5.40 & 5.40 & 6.04 & 5.40 & 5.40 & 5.40 \\
\hline 8 & 5.41 & 5.41 & 6.04 & 5.39 & 5.39 & 5.39 \\
\hline 9 & 5.58 & 5.58 & 6.22 & 5.55 & 5.55 & 5.55 \\
\hline 10 & 5.58 & 5.58 & 6.22 & 5.56 & 5.56 & 5.56 \\
\hline 11 & 5.57 & 5.57 & 6.22 & 5.56 & 5.56 & 5.56 \\
\hline
\end{tabular}

At this point we would simply state that the usage of extreme convergence criteria may be required to obtain the "perfect" degeneracies pattern of the calculated electronic excited states. In principle, more accurate dynamic electron correlation treatments may result in better agreements with the experiment. However, these different possibilities will not be explored as this is not the subject of this work. 


\section{D: DMRGSCF and NEVPT2 electronic energies (Eh) for Chromium dimer $\mathrm{Cr}_{2}$}

Table 2: CASSCF+SC-NEVPT2 $(12,12)$ electronic energies in Hartrees

\begin{tabular}{cccccc}
\hline \hline & & & & & \\
Bond distance & CASSCF & CASSCF + & & & CASFF+ \\
\hline \hline 1.500 & -2086.63250 & -2087.72455 & 2.269 & -2086.69121 & -2087.71183 \\
1.538 & -2086.64328 & -2087.73567 & 2.308 & -2086.69381 & -2087.71151 \\
1.577 & -2086.65007 & -2087.74270 & 2.346 & -2086.69625 & -2087.71127 \\
1.615 & -2086.65407 & -2087.74647 & 2.385 & -2086.69851 & -2087.71109 \\
1.654 & -2086.65627 & -2087.74771 & 2.423 & -2086.70060 & -2087.71094 \\
1.692 & -2086.65747 & -2087.74690 & 2.462 & -2086.70251 & -2087.71080 \\
1.731 & -2086.65825 & -2087.74464 & 2.500 & -2086.70426 & -2087.71066 \\
1.769 & -2086.65903 & -2087.74146 & 2.538 & -2086.70584 & -2087.71050 \\
1.808 & -2086.66005 & -2087.73779 & 2.577 & -2086.70727 & -2087.71031 \\
1.846 & -2086.66143 & -2087.73394 & 2.615 & -2086.70855 & -2087.71009 \\
1.885 & -2086.66319 & -2087.73017 & 2.654 & -2086.70970 & -2087.70984 \\
1.923 & -2086.66532 & -2087.72658 & 2.692 & -2086.71071 & -2087.70954 \\
1.962 & -2086.66778 & -2087.72346 & 2.731 & -2086.71160 & -2087.70920 \\
2.000 & -2086.67050 & -2087.72065 & 2.769 & -2086.71239 & -2087.70881 \\
2.038 & -2086.67341 & -2087.71834 & 2.808 & -2086.71307 & -2087.70838 \\
2.077 & -2086.67644 & -2087.71640 & 2.846 & -2086.71366 & -2087.70794 \\
2.115 & -2086.67952 & -2087.71498 & 2.885 & -2086.71416 & -2087.70743 \\
2.154 & -2086.68257 & -2087.71381 & 2.923 & -2086.71458 & -2087.70689 \\
2.192 & -2086.68557 & -2087.71292 & 2.962 & -2086.71493 & -2087.70633 \\
2.231 & -2086.68845 & -2087.71229 & 3.000 & -2086.71522 & -2087.70572 \\
\hline
\end{tabular}


Table 3: CASSCF+SC-NEVPT2 $(12,14)$ electronic energies in Hartrees

\begin{tabular}{|c|c|c|c|c|c|}
\hline Bond distance & CASSCF & $\begin{array}{c}\text { CASSCF }+ \\
\text { SC-NEVPT2 }\end{array}$ & Bond distance & CASSCF & $\begin{array}{c}\text { CASSCF }+ \\
\text { SC-NEVPT2 }\end{array}$ \\
\hline 1.500 & -2086.60013 & -2087.34210 & 2.004 & -2086.64797 & -2087.37363 \\
\hline 1.600 & -2086.62430 & -2087.36912 & 2.172 & -2086.65886 & -2087.37123 \\
\hline 1.625 & -2086.62707 & -2087.37230 & 2.200 & -2086.66067 & -2087.37079 \\
\hline 1.650 & -2086.62911 & -2087.37456 & 2.339 & -2086.66857 & -2087.36964 \\
\hline 1.668 & -2086.63024 & -2087.37573 & 2.400 & -2086.67140 & -2087.36939 \\
\hline 1.675 & -2086.63063 & -2087.37610 & 2.507 & -2086.67545 & -2087.36889 \\
\hline 1.700 & -2086.63182 & -2087.37707 & 2.600 & -2086.67799 & -2087.36818 \\
\hline 1.725 & -2086.63286 & -2087.37764 & 2.675 & -2086.67948 & -2087.36735 \\
\hline 1.750 & -2086.63386 & -2087.37792 & 2.800 & -2086.68097 & -2087.36549 \\
\hline 1.775 & -2086.63495 & -2087.37773 & 2.843 & -2086.68124 & -2087.36473 \\
\hline 1.836 & -2086.63818 & -2087.37392 & 3.000 & -2086.68145 & -2087.36156 \\
\hline 2.000 & -2086.64774 & -2087.37363 & 3.011 & -2086.68142 & -2087.36132 \\
\hline
\end{tabular}

\section{E: Optimized XYZ Geometries}

\section{Hieber anion}

Charge $=-1$

$\begin{array}{rrrr}\mathrm{Fe} & 0.91198054431352 & -1.22501825372697 & -3.03193169954737 \\ \mathrm{C} & 2.06418099462322 & -2.57211496198120 & -2.89028112556033 \\ \mathrm{~N} & 1.31465781694778 & -0.03651724587127 & -4.09110765101162 \\ \mathrm{C} & -0.61334106924134 & -2.07298429480550 & -3.37135313342047 \\ \mathrm{C} & 0.70355792126154 & -0.75115929687576 & -1.32838800380558 \\ \mathrm{O} & -1.61164782651509 & -2.60575981610975 & -3.62376489002435 \\ \mathrm{O} & 0.57539742797786 & -0.41683615499019 & -0.22559692749194 \\ \mathrm{O} & 1.60193424186987 & 0.81974484612463 & -4.86130033995096 \\ \mathrm{O} & 2.83485194876265 & -3.43566782176399 & -2.82359422918739\end{array}$

\section{Oxotetrachlorovanadate(IV) anion}

Charge $=-2$ 


$\begin{array}{rrrr}\mathrm{V} & 0 & 0 & 0 \\ \mathrm{O} & 0 & 0 & 1.592 \\ \mathrm{Cl} & 2.319037 & 0 & -0.539657 \\ \mathrm{Cl} & -2.319037 & 0 & -0.539657 \\ \mathrm{Cl} & 0 & 2.319037 & -0.539657 \\ \mathrm{Cl} & 0 & -2.319037 & -0.539657\end{array}$




\section{biomimetic $\mathrm{Mn}_{4} \mathrm{O}_{4}$-Cluster}

Charge $=+2$

$\begin{array}{crrr}\mathrm{Mn} & -1.010446058 & -0.974638995 & 0.235518009 \\ \mathrm{Mn} & 0.953976975 & 0.946704593 & 0.276029333 \\ \mathrm{Mn} & -1.272400668 & 1.317188916 & -1.870104164 \\ \mathrm{Mn} & 1.248260792 & -1.24442817 & -1.885216106 \\ \mathrm{O} & -0.887976898 & 0.858911221 & 0.2219543 \\ \mathrm{O} & 0.83465464 & -0.888036491 & 0.198755456 \\ \mathrm{O} & -0.614240668 & -0.583455184 & -1.956872372 \\ \mathrm{O} & 0.624295252 & 0.636713479 & -1.911624749 \\ \mathrm{O} & -3.161516494 & 0.981289613 & -1.889125864 \\ \mathrm{O} & -0.975300609 & -0.993688296 & 2.078482203 \\ \mathrm{O} & -1.007636582 & -2.841319888 & -0.160914338 \\ \mathrm{O} & 2.839290635 & 0.920450566 & -0.037656323 \\ \mathrm{O} & -0.942245893 & 3.202325206 & -1.79380251 \\ \mathrm{P} & 3.833947771 & -0.067506414 & -0.747769028 \\ \mathrm{P} & -0.166490809 & 0.06727885 & 2.957538572 \\ \mathrm{O} & 3.127340147 & -0.971974221 & -1.82702644 \\ \mathrm{O} & 0.924041446 & 0.8802286 & 2.121063061 \\ \mathrm{P} & -0.048460333 & -3.84489566 & -0.892826425 \\ \mathrm{P} & -3.875433645 & -0.011104792 & -0.904839074 \\ \mathrm{P} & 0.201031005 & 3.851790478 & -0.934375285 \\ \mathrm{O} & 0.93078293 & 2.835917288 & 0.017100843 \\ \mathrm{O} & -2.885869714 & -0.929214579 & -0.098171372 \\ \mathrm{O} & 0.976587235 & -3.115128178 & -1.845597663 \\ \mathrm{H} & 4.848590233 & 0.694184057 & -1.388273034 \\ \mathrm{H} & 0.49794546 & -0.639156868 & 3.996185215 \\ \mathrm{H} & -1.077170359 & 0.98043567 & 3.559007669 \\ \mathrm{H} & -4.750349141 & -0.843902608 & -1.654903897 \\ \mathrm{H} & 1.158084907 & 4.443812215 & -1.806265852 \\ \mathrm{H} & 0.667366452 & -4.622975151 & 0.060641993 \\ \mathrm{H} & -0.343426661 & 4.902971057 & -0.145891017 \\ \mathrm{H} & -4.683667939 & 0.721766185 & 0.009933992 \\ \mathrm{H} & 4.476171807 & -0.889636356 & 0.221451967 \\ \mathrm{H} & -0.833335212 & -4.745516147 & -1.663447101\end{array}$




\section{$\mathrm{CH}_{3} \mathrm{Mn}(\mathrm{CO})_{3}(\alpha$-diimine $)$}

Charge $=0$

$\begin{array}{crrr}\mathrm{Mn} & 1.592669 & -0.752166 & -4.635355 \\ \mathrm{C} & 1.889762 & 0.490987 & -6.382367 \\ \mathrm{H} & 2.866018 & 0.969806 & -6.415946 \\ \mathrm{H} & 1.781515 & -0.21633 & -7.205438 \\ \mathrm{H} & 1.110725 & 1.249508 & -6.444178 \\ \mathrm{C} & 1.462116 & -1.543663 & -3.005866 \\ \mathrm{O} & 1.397363 & -2.010299 & -1.955019 \\ \mathrm{C} & 3.384848 & -0.582039 & -4.456686 \\ \mathrm{O} & 4.529408 & -0.475769 & -4.40212 \\ \mathrm{C} & 1.229755 & 0.866088 & -3.903086 \\ \mathrm{O} & 0.977421 & 1.908143 & -3.486024 \\ \mathrm{C} & 0.712461 & -2.747455 & -6.422098 \\ \mathrm{~N} & -0.215856 & -0.975764 & -5.338659 \\ \mathrm{C} & -0.427963 & -1.933057 & -6.207601 \\ \mathrm{~N} & 1.752926 & -2.361484 & -5.724225 \\ \mathrm{H} & 0.723876 & -3.612117 & -7.07507 \\ \mathrm{H} & -1.382225 & -2.087876 & -6.697063 \\ \mathrm{H} & -1.013871 & -0.374875 & -5.161632 \\ \mathrm{H} & 2.581258 & -2.936031 & -5.837754\end{array}$




\section{Anthracene}

Charge $=0$

$\begin{array}{lrrr}\mathrm{C} & -1.219192 & -0.720166 & -0.000048 \\ \mathrm{C} & -1.21918 & 0.720186 & -0.000045 \\ \mathrm{C} & 1.219164 & -0.720187 & -0.000064 \\ \mathrm{C} & 1.219176 & 0.720164 & -0.000063 \\ \mathrm{C} & -0.000021 & -1.400198 & -0.000054 \\ \mathrm{C} & 0.000004 & 1.400196 & -0.000052 \\ \mathrm{C} & -2.469462 & -1.402672 & -0.00005 \\ \mathrm{C} & -2.469436 & 1.402714 & -0.000044 \\ \mathrm{C} & 2.469421 & -1.402715 & -0.000077 \\ \mathrm{C} & 2.469444 & 1.402673 & -0.000076 \\ \mathrm{C} & -3.647323 & -0.710612 & -0.000052 \\ \mathrm{C} & -3.647311 & 0.710676 & -0.000047 \\ \mathrm{C} & 3.647294 & -0.710674 & -0.000088 \\ \mathrm{C} & 3.647306 & 0.710614 & -0.000087 \\ \mathrm{H} & -0.000031 & -2.485568 & -0.000053 \\ \mathrm{H} & 0.000013 & 2.485566 & -0.000051 \\ \mathrm{H} & -2.46653 & -2.487071 & -0.000054 \\ \mathrm{H} & -2.466486 & 2.487113 & -0.000042 \\ \mathrm{H} & 2.466471 & -2.487114 & -0.00008 \\ \mathrm{H} & 2.466512 & 2.487072 & -0.000078 \\ \mathrm{H} & -4.59103 & -1.242818 & -0.000055 \\ \mathrm{H} & -4.591009 & 1.242898 & -0.000048 \\ \mathrm{H} & 4.590992 & -1.242896 & -0.000097 \\ \mathrm{H} & 4.591013 & 1.242819 & -0.000095\end{array}$

